\title{
Evacuation of Patient from Dual Hyperbaric Chamber-Singapore Experience
}

\section{Jia Yin Lim, Yoong Chuan Tay}

Division of Anaesthesiology and Perioperative Medicine, Singapore General Hospital, Singapore

Correspondence to: Jia Yin Lim, limjiayin90@gmail.com; Yoong Chuan Tay, tay.yoong.chuan@singhealth.com.sg Keywords: Dual Chamber, Emergent, Evacuation, Extraction, Hyperbaric Oxygen Therapy

Received: January 14, $2022 \quad$ Accepted: February 18, $2022 \quad$ Published: February 21, 2022

Copyright $\odot 2022$ by author(s) and Scientific Research Publishing Inc.

This work is licensed under the Creative Commons Attribution International License (CC BY 4.0).

http://creativecommons.org/licenses/by/4.0/

\section{(c) (i) Open Access}

\section{ABSTRACT}

The Hyperbaric and Diving Medicine Centre of Singapore provides regular treatment for various UHMS indications for hyperbaric treatment in our dual multi-place connected chambers. When any single patient requires evacuation during the treatment, a connected dual chamber facility is advantageous to avoid disruption for the remaining patients. We share our experience and procedures to facilitate repeated unexpected evacuation with minimal disruption to other patients undergoing treatment, in an elderly semi-activity dependent patient who had gastrointestinal symptoms during treatment.

\section{INTRODUCTION}

Over the past decades, there is a considerable growth in the clinical use of hyperbaric oxygen therapy. The Hyperbaric and Diving Medicine Centre in Singapore General Hospital (since 2008) is the first comprehensive and integrated facility in Singapore. This is a service led by a team of specialists and is equipped with dual hyperbaric chamber and facilities for treatment of decompression sickness, gas embolism, carbon monoxide poisoning, burns, radiation injury, infection, and poor wound healing.

The management of emergencies under hyperbaric conditions has always been challenging and in many instances, evacuation from the chamber is necessary. Similar to diving, rapid ascend or emergent evacuation of personnel from a compressed chamber poses significant risk of decompression illness (DCI). Decompression illness is caused by intravascular or extravascular bubbles formed because of reduction in the environmental pressure (decompression). DCI includes both arterial gas embolism where gaseous emboli are introduced to the arterial circulation, and decompression sickness (DCS) which is caused by in-situ bubble formation from dissolved inert gas [1]. Manifestations range from minor symptoms such as itch and joint pain to major neurological symptoms, paralysis, cardiac collapse, and death [1]. Hence, trained, expert operators and medical support are required for safe conduct of each session and management of unexpected emergencies within the hyperbaric chamber. 


\section{CASE SUMMARY}

A 68-year-old male, with background of poorly controlled diabetes, chronic kidney disease and peripheral vascular disease sustained bilateral feet plantar superficial partial thickness burns (total body surface area of 2\%). Patient presented to the hospital 2 days after sustaining contact thermal injury. The mechanism of injury was from an afternoon walk on the sandy beach. Following bilateral feet deblistering and debridement; prophylactic antibiotic (Co-amoxiclav) and 10 - 20 sessions of hyperbaric treatment were initiated.

Patient's hospital stay was complicated by the development of non-infective watery diarrhea. At 15 minutes and 70 minutes into patient's $3^{\text {rd }}$ and $4^{\text {th }}$ hyperbaric treatment respectively; patient required immediate evacuation from the chamber due to abdominal discomfort and diarrhea.

\section{Evacuation Attempts}

Figure 1 presents the floor plan of our multi-place hyperbaric chamber. In our institution, during each hyperbaric session, there will always be at least one nurse or tender within each lock. There are also video monitors and communicative headsets available for the tender within the chamber to converse with the operator outside.

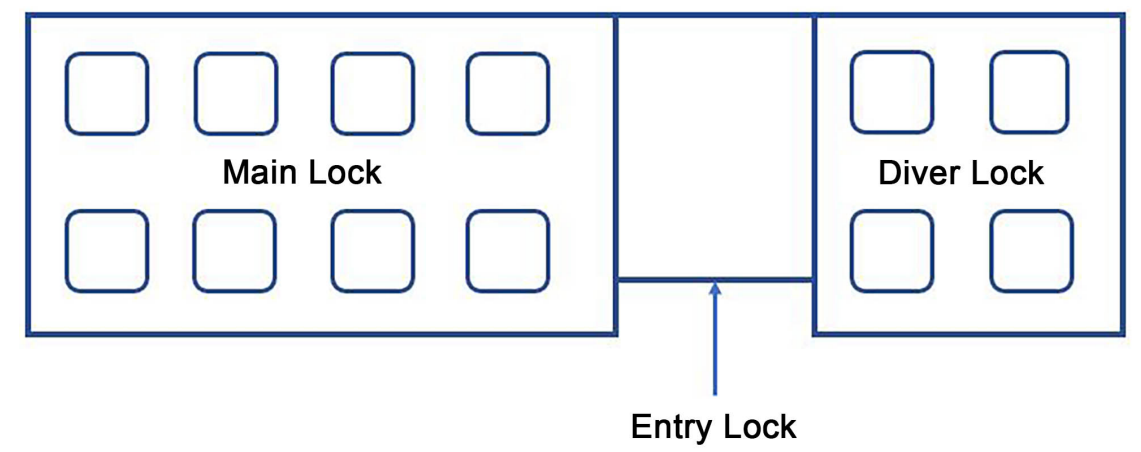

Figure 1. Dual hyperbaric chamber, Singapore General Hospital.

For the evacuation of patient during his $3^{\text {rd }}$ hyperbaric treatment, at 15 minutes, 10 -meter sea water $(\mathrm{msw})$; we placed a commode in the entry lock and quickly pressurized the entry lock to $10 \mathrm{msw}$. When the entry lock pressure equalizes with the main lock, the nursing staff within the main lock then assisted the patient out into the entry lock to use the commode. After which we resurface the entry lock for safe evacuation of the patient.

For his second evacuation during his $4^{\text {th }}$ treatment session, at 70 minutes, $10 \mathrm{msw}$; six other patients were in the main lock and two in the diver lock. With both main and diver lock doors closed, one of our attendants entered the entry lock and the entry lock was compressed to $10 \mathrm{msw}$. When the pressure within the two chambers (main and entry locks) equalized, entry/main lock door was opened, and patient was evacuated into the entry lock. We then shut the entry/main lock doors and the entry lock was decompressed to sea level for safe evacuation of patient and the attendant.

During both evacuations, the other patients within the main and diver lock continued to receive their hyperbaric treatment.

\section{DISCUSSION}

\subsection{Chamber Dynamics (In Our Institution)}

The speed to compress and decompress the hyperbaric chamber varies with the type of chamber including its pressure regulator system, chamber volume, number of relief valves, and diameter of escape pipelines. 
Least time taken to compress the chamber (to $10 \mathrm{msw}$ ):

- $\quad$ Entry Lock (without staff): Approximately 33 seconds

- $\quad$ Entry Lock (with trained diver/staff): Approximately 33 seconds (safe limit of $1 \mathrm{ft} . /$ second as tolerated by personnel)

- $\quad$ Entry Lock (with any staff): Approximately 2 minutes 30 seconds (as tolerated by tender)

Least time taken to decompress the chamber (from $10 \mathrm{msw}$ ):

- $\quad$ Entry Lock: 3 minutes 35 seconds

- $\quad$ Entire Main Lock: 1 minute 30 seconds (when medical lock opened)

\subsection{Considerations and Options for Evacuation}

1) Time and depth during evacuation

If the hyperbaric chamber is already at its target depth of $10 \mathrm{msw}$ (beyond 10 minutes as our standard treatment protocol shown in Figure 2), the best option is to pressurize the entry lock and evacuate from the entry lock whilst the treatment for the rest of the patients remains uninterrupted. However, if evacuation is required during the initial stage of descend (less than 10 minutes from the start of treatment); two evacuation options are available. The treatment may be stopped, and the chamber is surfaced as a whole and re-pressurized after evacuation of the individual. This may be ideal especially if the patient is immobile and requires wheelchair assistance. Another option is to extract the patient from the entry lock as discussed earlier.

2) Urgency of situation

If there is a danger to all personnel within the chamber, fire for instance; it is obvious that the entire lock must be decompressed immediately to facilitate safe evacuation of all via the main lock exit. However, if a single patient becomes unwell within the compressed chamber, medical assessment may be necessary to decide if evacuation is required. In this instance, a doctor will need to enter the chamber with basic approved equipment via the entry lock to assess the patient. A medical decision can then be made whether the patient requires immediate evacuation either from the entry lock or via the main lock itself. In other semi-urgent situations where diagnosis is obvious, for example in our case, the patient requires urgent access of the commode, patient can be evacuated via the compressed entry or main lock without medical assessment.

3) Patient mobility

Another important consideration is that of patient's mobility status. If the patient is mobile or requires minimal assistance with transfer, patient can exit via the entry lock. With this method, it will not interrupt the treatment received by other patients. However, if the patient is immobile, wheelchair/bed bound, it is almost impossible to evacuate via the small entry lock with steps. Hence, in such situations where immediate evacuation is required, the entire main lock will have to be surfaced for extraction via the main entrance which is accessible by wheelchair.

4) Decompression illness (to patient and staff)

The safe resurfacing rate is $0.5 \mathrm{ft}$./second as advised in the US Navy Diving Manual 2016 [2]; in other words, it is safe to ascend to sea level over 66 seconds from a depth of $10 \mathrm{msw}$ ( $32.6 \mathrm{fsw}$ ). As discussed earlier, in our institution, it takes about 1.5 and 3.5 minutes to decompress the main and entry lock respectively, which is far beyond the stated safe limit of 66 seconds. However, the theoretical risks of decompression injuries remain with rapid ascend.

5) Accidental/Inadvertent decompression of other lock

In the situation where evacuation when both main and diver lock is in use; the double doors on either side of the entry lock (towards main and diver lock) must be closed. If for example, the door towards diver lock is not closed as illustrated in Figure 3; during decompression of the entry lock, the door will swing open due to pressure difference (where diver lock is at $10 \mathrm{msw}$ and entry lock is lower). This will lead to accidental decompression of the diver lock. However, the leak should be small and slow which should not result significant drop in chamber pressure leading to any decompression injuries. 


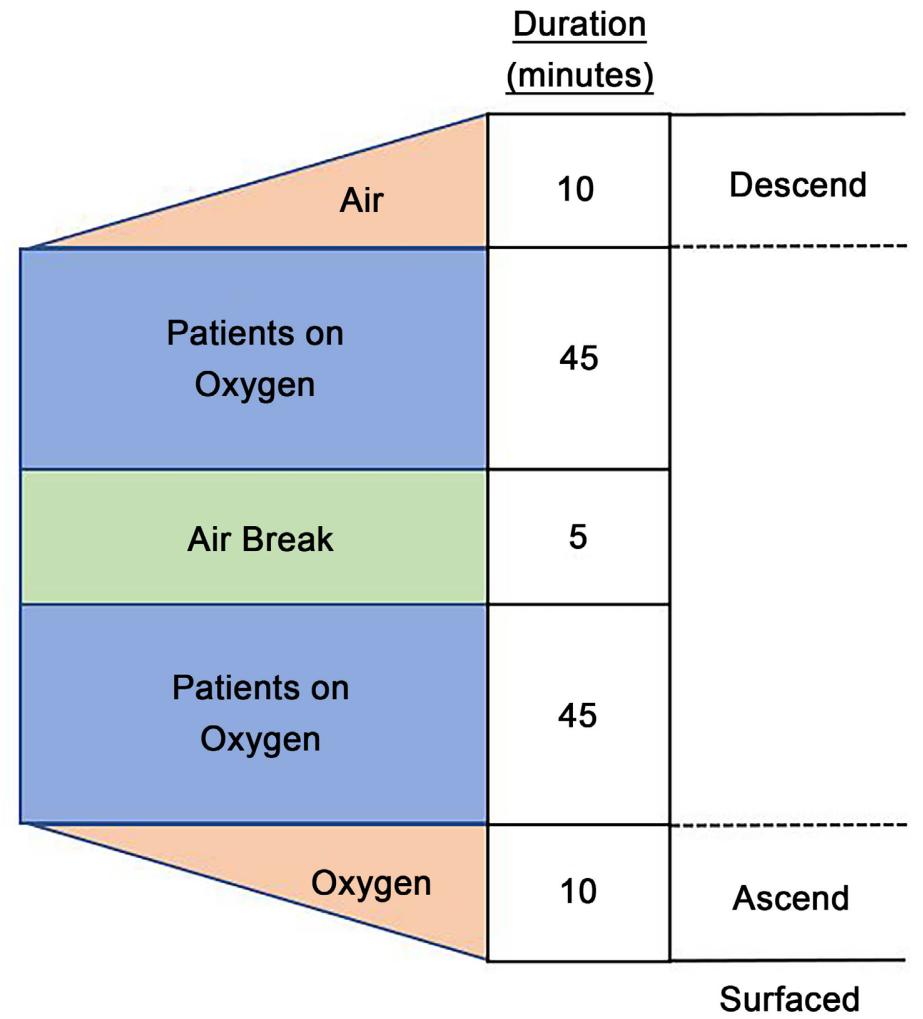

Treatment Depth: $10 \mathrm{msw}=100 \mathrm{kPa}, 14.5 \mathrm{PSO}, 1 \mathrm{BAR}, 750.6 \mathrm{mmHg}, 32.646 \mathrm{fsw}$ Total Treatment Duration: 115 minutes

Figure 2. An example of a standard treatment session in hyperbaric and diving medicine centre, Singapore General Hospital.

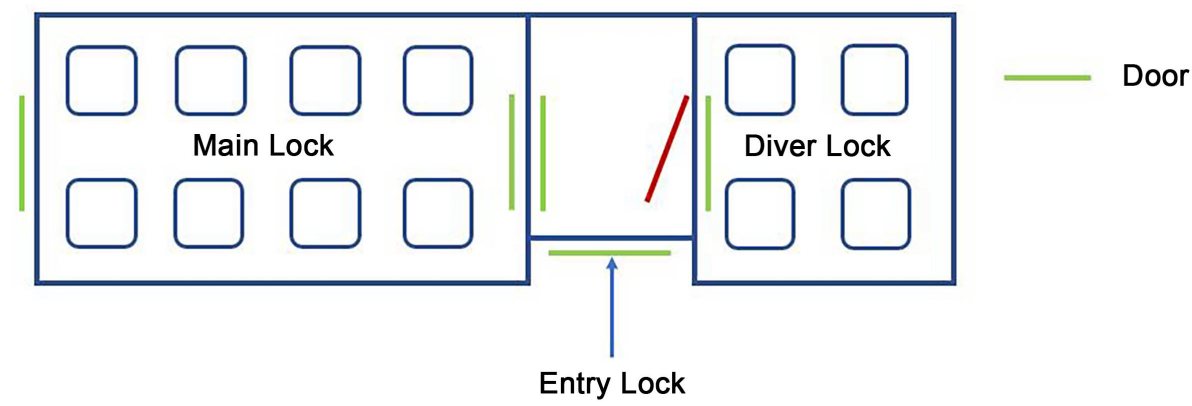

Figure 3. Illustration of opened diver lock door towards the entry lock (in red) when it is not closed properly.

6) Prevention

The principal concern is none other than avoiding such incidents which require evacuation of patients from the enclosed chamber prematurely. Primary prevention involves early detection and treatment of medical conditions, and delay treatment sessions until the acute medical condition resolves. This requires meticulous assessment prior to each treatment session to exclude any potential interruption to the session. Other options in this case for recurrent non-infective diarrhea include the use of medications (such as Loperamide), diapers or Flexiseal which allows the patient to undergo these sessions without disruption to the treatment course. 
It is also important to ensure regular checks and service of the chamber and equipment to avoid malfunction or failure. Despite all efforts, unexpected emergencies can still occur. In such situations, simulations and drills are necessary as an effective training modality [3].

\section{CONCLUSION}

Evacuation of a patient during hyperbaric treatment remains an important procedure that the team needs to be familiar with. Real-time headsets and video cameras for communication and available tenders on standby are essential for minimal disruption and efficiency of the evacuation.

\section{CONFLICTS OF INTEREST}

The authors declare no conflicts of interest regarding the publication of this paper.

\section{REFERENCES}

1. Vann, R.D., Butler, F.K., Mitchell, S.J., et al. (2011) Decompression Illness. Lancet, 377, 153-164.

https://doi.org/10.1016/S0140-6736(10)61085-9

2. Direction of Commander, Naval Sea Systems Command (December 2016) US Navy Diving Manual (Revision 7).

3. Issenberg, S.B., McGaghie, W.C., Petrusa, E.R., et al. (2005) Features and Uses of High-Fidelity Medical Simulations That Lead to Effective Learning: A BEME Systematic Review. MedTech, 27, 10-28.

https://doi.org/10.1080/01421590500046924 